\title{
Variations of Thenar Branch of Median Nerve in the North Indian Population
}

\author{
Neelamjit Kaur ${ }^{*}$, Rajan Kumar Singla², Jagdev Singh Kullar ${ }^{3}$ \\ $1^{1 *}$ Associate Professor, Department of Anatomy, \\ Maharishi Markandeshwar Medical College \& Hospital, Kumarhatti, Solan, Himachal Pradesh, India. \\ 2Professor \& Head, Department of Anatomy, Government Medical College, Patiala, Punjab, India. \\ 3Professor, Department of Anatomy, Government Medical College, Amritsar, Punjab, India.
}

\section{ABSTRACT}

Introduction: Inadvertant injury to median nerve during carpal tunnel surgery can be minimized if anatomy is understood, variations recognized and adequate exposure is achieved. Adequate decompression of compromised structure and preservation of recurrent motor branch are of paramount concern in carpal tunnel surgery.

Material and Methods: The present study was conducted on 60 upper limbs of 30 well embalmed adult human cadavers at the Government Medical College, Amritsar. The whole course of the thenar branch of median nerve was exposed.

Aim of Study: Aim of the study was to understand normal pattern of thenar nerve including variations in its formation and in its branching pattern which would form useful data for hand surgeons doing open/endoscopic carpal tunnel release.

Results: We found variations of thenar nerve in $18(30 \%)$ out of 60 hands. Accessory thenar nerve was found in $5(8.3 \%)$ hands, origin of thenar nerve in carpal tunnel in $12(20 \%)$ hands, multiple thenar branches was seen in $1(1.8 \%)$ hand.

Clinical Significance: The variations of median nerve in hand

\section{INTRODUCTION}

Knowledge of the anatomy of thenar branch of median nerve is important in surgery of the palmar aspect of hand. Carpal tunnel syndrome is the most common entrapment neuropathy of the upper extremity. It is usually chronic and disabling peripheral neuropathy, characterized by nocturnal hand discomfort, paresthesia of the fingers in the distribution of the median nerve \& thenar muscle atrophy. Bilateral involvement can be encountered in $8-50 \%$ of patients. ${ }^{1}$

Although non operative intervention is the preferred initial method of treatment of Carpal Tunnel Syndrome but surgery is often necessary ${ }^{2}$. Therefore, adequate decompression of compromised structure and preservation of recurrent motor branch (thenar nerve) are of paramount concern in carpal tunnel surgery ${ }^{3}$. To prevent thenar branch injury during wrist surgery, knowledge of ramification pattern of thenar branch before entering the thenar fascia with the distribution of terminal branches in thenar musculature and meticulous dissection is required ${ }^{4}$. With the growing popularity of limited incisions and endoscopic decompression, knowledge of various anomalies of median nerve and its branches at wrist takes on added importance ${ }^{2}$.

Past research studies have reported the fact that variant nerve sharing abnormal origin, course and distribution are more prone to and their incidence will aid the surgeon in avoiding iatrogenic complications and improve the success rate of median nerve decompressions.

Keywords: Thenar nerve, Hand variations, Carpal tunnel, Median nerve, Accessory thenar nerve, Opponens pollicis.

\section{${ }^{*}$ Correspondence to:}

Dr. Neelamjit Kaur

1083, Phase 9 (Sector 63),

Mohali, Punjab, India.

\section{Article History:}

Received: 18-10-2016, Revised: 26-10-2016, Accepted: 07-11-2016

\begin{tabular}{|l|c|}
\hline \multicolumn{2}{|c|}{ Access this article online } \\
\hline $\begin{array}{l}\text { Website: } \\
\text { www.ijmrp.com }\end{array}$ & Quick Response code \\
\hline DOI: & \\
10.21276/ijmrp.2016.2.6.012 & \\
\hline
\end{tabular}

accidental injuries and entrapment neuropathies. During surgical procedures of carpal tunnel, a surgeon is exposed to topographical anatomy of the neural structures and awareness of variations may be of immense clinical help. Better understanding and correct interpretation of clinical neurophysiology can only be possible with prior academic knowledge ${ }^{5}$. The variations and their incidence will aid the surgeon in avoiding iatrogenic complications and improve the success rate of median nerve decompressions. To sum up, the present study has been undertaken to understand normal pattern of thenar branch of median nerve including variations in its origin and in its branching pattern.

\section{MATERIALS \& METHODS}

The present study was conducted on 60 upper limbs of 30 (M:F::28:2) well embalmed adult human cadavers at the Government Medical College, Amritsar, Punjab, India. The dissection of the palm was done meticulously to expose the thenar branch of median nerve and the muscles it supplies as per the dissection steps given in Cunningham's Manual of Practical Anatomy ${ }^{6}$. Skin of the hand was reflected. The aponeurosis was turned distally by separating its edges from thinner deep fascia covering thenar and hypothenar muscles and palmaris longus 
tendon was separated from surface of flexor retinaculum. Superficial palmar arch immediately deep to the palmar aponeurosis was exposed and the thenar branch of the median nerve was followed from its origin to termination. The thenar muscles were carefully isolated preserving their nerve supply and taking care to dissect all the branches \& show their anatomical relationships.

\section{RESULTS}

Normally the median nerve pass through the carpal tunnel deep to the flexor retinaculum. ${ }^{7-9}$ This standard course was observed in all the 60 specimens of the present study as there was no case in which median nerve traversed flexor retinaculum or passed superficial to it.

\section{a) Number of Thenar Nerves:}

In the present study single thenar nerve was seen in 54 (90\%) limbs which originated from the lateral terminal branch of median nerve. An additional accessory thenar nerve was seen in $5(8.3 \%)$ limbs and it originated from 1 st proper palmar digital nerve (Fig 1). In one limb (1.8\%) there were multiple branches piercing thenar fascia (Fig 2).

\section{b) Site of origin:}

Out of 54 limbs with single thenar nerve, in forty three limbs $(79.6 \%)$ it originated just distal to the flexor retinaculum from lateral branch. In $11(20.3 \%)$ it originated in the carpal tunnel from main trunk of median nerve.

Out of 5 hands with two thenar nerves ie. one thenar and one accessory thenar nerve, the thenar nerve in $4(80 \%)$ hands originated distal to flexor retinaculum and in $1(20 \%)$ hand (26MR) within the carpal tunnel. All accessory thenar nerves originated from $1^{\text {st }}$ proper palmar digital nerve distal to flexor retinaculum (Fig 1). In one hand (7ML) (1.6\%) multiple (5) thenar branches were seen all distal to flexor retinaculum (Fig 2).

\section{c) Muscles supplied:}

The single thenar nerve in all the limbs supplied all the three thenar muscles viz. Opponens pollicis, Abductor pollicis brevis, Flexor pollicis brevis. When there was an additional accessory thenar nerve (in 5 limbs) the main thenar nerve supplied twigs to all three muscles again. But the accessory thenar nerve supplied only opponens pollicis (Fig 1). In the single hand where thenar nerve divided into five twigs; one twig supplied abductor pollicis brevis, two to Flexor pollicis brevis and two to opponens pollicis (Fig 2). Thus whenever an additional supply is there, it is for opponens pollicis. In one case with multiple branches, the additional supply was for opponens pollicis and flexor pollicis brevis.

d) Nerve supply of individual muscles:

As far as individual muscles are concerned, the APB was supplied by a single thenar nerve in all hands. Superficial head of FPB was supplied by single nerve in fifty nine hands and two nerves in one hand. OP was supplied by single branch in 54 cases. OP had dual innervation from thenar branch and accessory thenar nerve in five specimens. In one hand, thenar nerve divided into five branches before piercing thenar fascia and supplied OP (2 branches), superficial head of FPB (2 branches) and APB (1 branch) (Fig 2). In the present study, number and origin of the digital branches of median nerve was same as described in the standard textbooks in all the limbs. ${ }^{7-9}$ There was no variation in the territory of supply as in all the cases digital branches of median nerve innervated lateral $3 \frac{1}{2}$ fingers.

\section{Table 1: Number of Nerves Supplying Individual Thenar Muscles}

\begin{tabular}{lcc}
\hline Muscle & Hands With Single Nerve & Hands With Two Nerves \\
\hline Abductor Pollicis Brevis & 60 & 0 \\
$\begin{array}{l}\text { Flexor Pollicis Brevis } \\
\text { (superficial head) }\end{array}$ & 59 & 1(in case of multiple branches) \\
Opponens Pollicis & 54 & 6 (5 ATN + 1 in case of multiple branches) \\
\hline
\end{tabular}

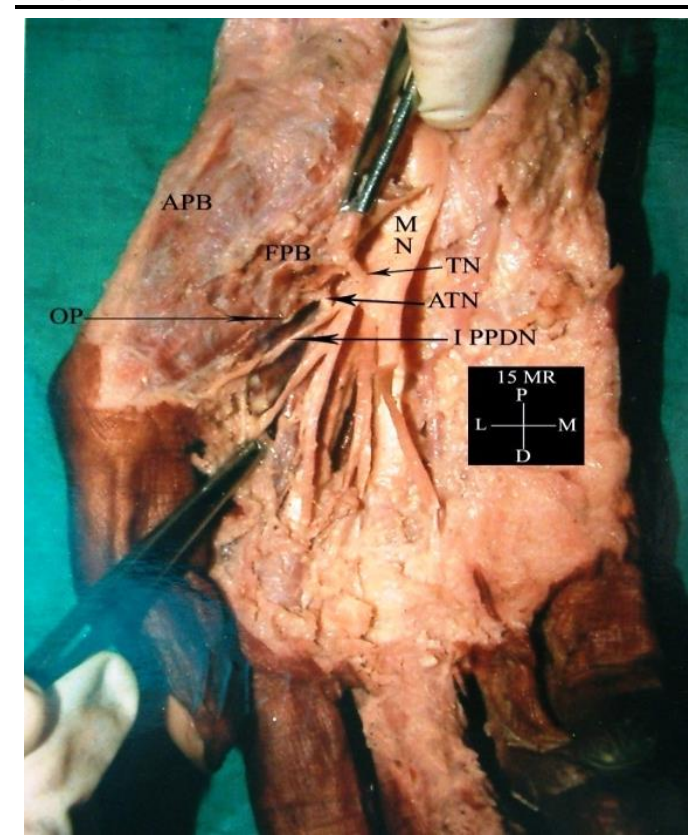

Fig 1: Accessory Thenar Nerve (ATN) originating from first proper palmar digital nerve (I PPDN) and supplying Opponens Pollicis (OP). (MN-Median nerve, TN-Thenar nerve, APB-Abductor pollicis brevis, FPB-Flexor pollicis brevis)

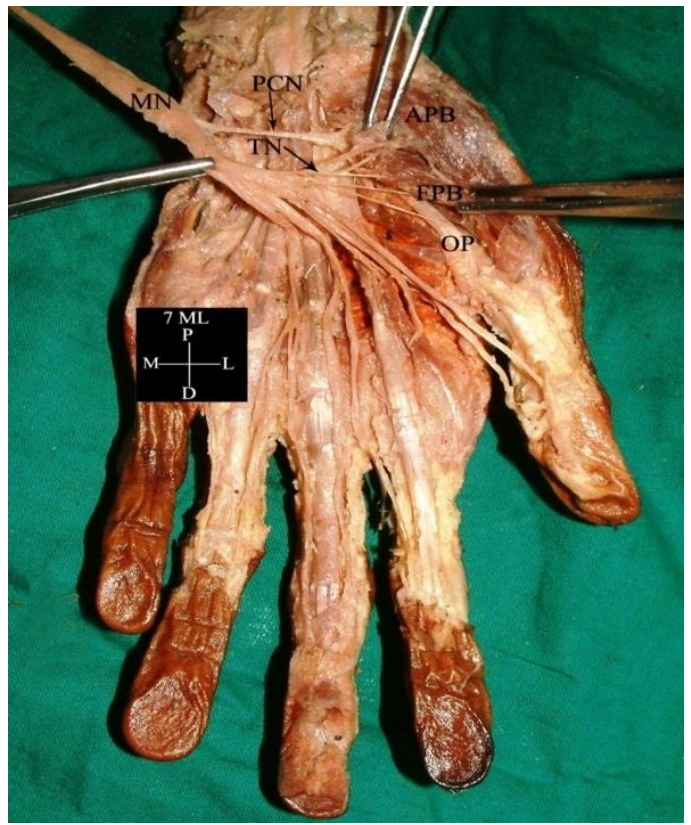

Fig 2: Multiple branches of thenar nerve (TN), piercing thenar fascia. (APB-Abductor pollicis brevis, FPB-Flexor pollicis brevis, OP-Opponens pollicis, MN-Median nerve, PCN-Palmar cutaneous nerve) 


\section{DISCUSSION}

Importance of the muscular branch of median nerve in hand is unquestionable. Since it innervates the muscles of the thenar eminence it is responsible for the efficiency of the thumb and multiple activities of the hand.

a) Number of thenar nerves: Depending upon the number of thenar branches arising from the median nerve and entering the thenar fascia Alp et $a^{4}{ }^{4}$ classified thenar branches into four types:

\begin{tabular}{lcc}
\hline \multicolumn{3}{c}{ Classification of the thenar branches (Alp et $\mathrm{al}^{4}$ ) } \\
\hline Type I & Thenar branch piercing thenar fascia & $84 \%$ \\
\multicolumn{4}{c}{ as a single trunk } \\
Type II & Two Branches piercing thenar fascia & $13.2 \%$ \\
Type III & Three branches piercing thenar fascia & $2.1 \%$ \\
Type IV & Four branches piercing thenar fascia & $0.7 \%$ \\
\hline
\end{tabular}

According to this classification, type I with single thenar nerve was seen in $54(90 \%)$ limbs of the present study while type II was seen in $5(8.3 \%$ limbs). In the latter case where two thenar branches were seen the additional one was arising from first proper palmar digital nerve. In one limb multiple (5) thenar branches arose which is not classified in Alp et al ${ }^{4}$ classification. So it can be added as Type V.

b) Site of origin: Siverhus et $\mathrm{al}^{3}$ considered anatomy of thenar branch of median nerve to be classical or typical if recurrent branch emerges from median nerve just distal to flexor retinaculum. Any other variation from the classic course was recorded as an anomaly.

Table II compares the incidence of clinical pattern and the anomalous pattern of origin of thenar branch of median nerve as observed by earlier authors.

Table II: Percentage of Classic and Anomalous Patterns of Thenar Branch of Median Nerve

\begin{tabular}{lcc}
\hline Authors Name & Classic Pattern (\%) & Anomalous Pattern (\%) \\
\hline Mumford et al(1987) & 80 & 20 \\
Siverhus et al(1989) $^{3}$ & 86 & 14 \\
Olave et al (1996) $^{11}$ & 80 & 20 \\
Alp et al(2005) & 84 & 16 \\
Present Study(2008) & 80 & 20 \\
\hline
\end{tabular}

As evident from the Table $\|$ results of our study are in consonance with Mumford et $\mathrm{al}^{10}$ and Olave et $\mathrm{al}^{11}$. Thenar branch originating in the carpal tunnel has been reported as $66.7 \%^{12}, 20 \%^{10}$ and $18.3 \%{ }^{11}$.

In our study it was $20 \%$ which is in consonance with the findings of Mumford et $\mathrm{al}^{10}$ and Olave et al ${ }^{11}$. We agree with most of the referenced authors that this nerve is derived from the lateral division of the median nerve. ${ }^{7-9}$ Accessory thenar branch has been reported to originate from palmar digital nerve in $32.2 \%$ or from collateral radial nerve of index finger in $25 \% 13,14$.

But in our study in all the 5 cases it originated from the 1 st proper palmar digital nerve. Accessory thenar nerve has been reported by many anastomist being 38.3\%, 8.3\%, 75\%4,10,11 and in present study it was $8.3 \%$ which is in agreement with study of Alp et al ${ }^{4}$.

c) Nerve supply of different muscles: Whenever an additional thenar nerve was present, it supplied opponens pollicis which thus was supplied by two nerves. Opposition is an evolutionary achievement in human hand not seen in lower primates. An additional supply for this in some limbs may indicate that it may develop more in coming generations.

\section{CLINICAL SIGNIFICANCE}

Compression of median nerve at wrist is most common entrapment neuropathy of the upper extremities. Adequate and safe decompression of median nerve can best be ensured by achieving complete visualization of median nerve and its variants. Werschkul15 has pointed out that "blind" sectioning of flexor retinaculum can risk damaging anomalous recurrent branches of median nerve. Concern has been expressed that injury to these variants may occur when endoscopic techniques at the wrist do not provide adequate visualization.

\section{CONCLUSION}

To summarize the classical pattern of single thenar branch of median nerve is seen in $90 \%$ limbs with an additional accessory nerve in $8.3 \%$. Whether single or double it arises just distal to flexor retinaculum in $80 \%$ limbs and in carpal tunnel in $20 \%$. If it is single, it gives twigs to all three thenar muscles but when double the second nerve goes only to opponens pollicis. In the sole limb with five branches, additional branches supply opponens pollicis and flexor pollicis brevis. As far as palmar digital branches are concerned, no variations could be found.

\section{REFERENCES}

1. Tuncali D, Barutcu AY, Terzioglu A, Aslan G. Transverse carpal muscle in association with carpal tunnel syndrome: report of three cases. Clin Anat 2005; 18: 308-312.

2. Davlin LB, Aulicino PL, Bergfield TL. Anatomical variations of median nerve at the wrist. Orthopaedic Review 1992;955-958.

3. Siverhus SW, Kremchek TE, Smith WR, Basch TM, Drake RL. A cadaveric study of anatomic variations of the recurrent motor branch of the median nerve. Orthopaedic Review 1989; 18(3): 315-320.

4. Alp M, Marur T, Akkin SM,Yalcin L,Damirci S. Ramification pattern of the thenar branch of median nerve entering the thenar fascia and distribution of terminal branches in the thenar musculature.Clin Anat 2005; 18: 195-199.

5. Das S, Paul S. Anomalous branching pattern of lateral cord of brachial plexus. Int J Morphol 2005; 23(4): 282-292.

6 . Romanes GJ. The pectoral region and the axilla, the arm and the forearm and the hand. In: Cunninghams Manual of Practical Anatomy.15th Edition. Edinburgh, London: The English Language Book Society and Oxford University Press; 1986; 1, 28-89. 
7. Williams PL, Bannister LH, Berry MM, Collins P, Dyson M, Dussek JE et al. In: Berry MM, Standring S, Bannister LH. Gray's Anatomy. 38 $8^{\text {th }}$ Edition. Edinburgh; London: Churchill Livingstone; 1995; 1266-1274.

8. Schaffer EA, Symington J, Bryce TH. Spinal nerves. In:Quain's Elements of Anatomy.11th Edition. London: Longmans, Green \& Co; 1909; 3: 76-81.

9. Anson BJ. The cardiovascular and the nervous system. In: Quain's Elements of Anatomy.11th Edition. London: Longmans, Green \& co;1909;3:76-81.

10. Mumford J, Morecraft R, Blair W. Anatomy of thenar branch of median nerve. Jour of Hand Surgery 1987; 12A: 361-365.

11. Olave E, Prates JC, Gabrielli C, Pardi P. Morphometric studies of the muscular branch of the median nerve. J Anat 1996; 189: 445-449.

12. Duroux $P E$, Barry $P$, Lacoste $P$. Le rameau thenarien $d u$ median. Comptes Rendus de I Assoc. des anatomistes 1953; 39: 146-150.

13. DeSouza A. Contribuicao ao estudo da inervacao do musculi hypothenaris e thenaris no homem. Msc thesis Escola Paulista de Medicina 1975. Cited by: OlaveE, Prates JC, Gabrielli C, Pardi JC, Gabrielli C, Pardi P. Morphometric Studies Of The Muscular Branch Of Median Nerve.Jour of Anat1996;Vol 189;445-449.
14. Caetano E. Contribuicao ao estudo da inervacao dos musculos tenares e da anastomose de cannieu e Riche 1982 Ph.D. Thesis, Pontificia Universidade Catolica,Sao Paulo, Brazil. Cited by: OlaveE, Prates JC, Gabrielli C, Pardi JC, Gabrielli C, Pardi P. Morphometric Studies Of The Muscular Branch Of Median Nerve. Jour of Anat1996; Vol 189;445-449.

15. Werschkul JD. Anomalous course of the recurrent motor branch of the median nerve I a patient with carpal tunnel syndrome. J Neurosurg 1977;47: 113-114.

Source of Support: Nil. Conflict of Interest: None Declared.

Copyright: (c) the author(s) and publisher. IJMRP is an official publication of Ibn Sina Academy of Medieval Medicine \& Sciences, registered in 2001 under Indian Trusts Act, 1882.

This is an open access article distributed under the terms of the Creative Commons Attribution Non-commercial License, which permits unrestricted non-commercial use, distribution, and reproduction in any medium, provided the original work is properly cited.

Cite this article as: Neelamjit Kaur, Rajan Kumar Singla, Jagdev Singh Kullar. Variations of Thenar Branch of Median Nerve in the North Indian Population. Int J Med Res Prof. 2016; 2(6):67-70. DOI:10.21276/ijmrp.2016.2.6.012 